\title{
Effect of home-based virtual reality training and telerehabilitation on balance in individuals with Parkinson disease, multiple sclerosis, and stroke: a systematic review and meta-analysis
}

\author{
Steven Truijen ${ }^{1}$ - Auwal Abdullahi ${ }^{1,2}$ - Danique Bijsterbosch ${ }^{1}$. Eline van Zoest ${ }^{1} \cdot$ Maaike Conijn $^{1}$. \\ Yonglan Wang $^{1} \cdot$ Nele Struyf $^{1} \cdot$ Wim Saeys $^{1}$ (i)
}

Received: 1 December 2021 / Accepted: 25 December 2021 / Published online: 17 February 2022

(c) Fondazione Società Italiana di Neurologia 2022

\begin{abstract}
Objective In the last decade, there is a growing interest in the use of virtual reality for rehabilitation in clinical and home settings. The aim of this systematic review is to do a summary of the current evidence on the effect of home-based virtual reality training and telerehabilitation on postural balance in individuals with central neurological disorders.

Methods Literature was searched in PubMed, Web of Science, PEDro, ScienceDirect, and MEDLINE. Randomized controlled trials (RCTs) evaluating the effect of home-based virtual reality (VR) training and telerehabilitation (TR) on postural balance in patients with Parkinson's disease, Multiple sclerosis or stroke. Studies were imported to EndNote and Excel to perform two screening phases by four reviewers. Risk of bias was assessed using PEDro scale and Cochrane assessment tool for risk of bias. Synthesis of the data on comparative outcomes was performed using RevMan software.

Results Seven RCTs were included, with all three pathologies represented. VR and TR consisted of a training device (e.g., Nintendo Wii or Xbox 360) and a monitoring device (e.g., Skype or Microsoft Kinect). Five studies used the Berg Balance Scale (BBS) for measuring postural balance. Across studies, there was an improvement in BBS scores over time in both experimental and control groups, and the effect remained at follow-up for both groups. However, there was no significant difference between groups post-intervention ( $\mathrm{MD}=0.74, p=0.45)$.
\end{abstract}

Conclusion Home-based VR and TR can be used as prolongation to conventional therapy.

Keywords Stroke $\cdot$ Parkinson's disease $\cdot$ Multiple sclerosis $\cdot$ Balance $\cdot$ Virtual reality $\cdot$ Telerehabilitation

\section{Introduction}

Neurological disorders are the leading causes of disability in daily life and the second cause of death worldwide [1, 2]. Among central neurological disorders, Parkinson disease (PD), multiple sclerosis (MS), and stroke form more than $58 \%$ of the neurological disorders that cause disability-adjusted life years [3]. Consequences of PD, MS, and stroke in daily life can be seen in deficits in balance [4-6].

Auwal Abdullahi

aabdullahi.pth@buk.edu.ng

1 Department of Rehabilitation Sciences and Physiotherapy, Faculty of Medicine and Health Sciences, University of Antwerp, Wilrijk, Belgium

2 Department of Physiotherapy, Bayero University Kano, Kano, Nigeria
Neurological rehabilitation can be focused to improve postural stability and quality of life [7]. In the last decade, there is a growing interest in the use of virtual reality (VR) for rehabilitation in clinical and home settings due to developments of technologies and better accessibility [8]. Virtual reality is a form of digital therapeutics that provides the opportunities to practice in a realistic environment resembling real objects and events by integrating multiple stimuli through visual, auditory, tactile, and somatosensory systems [9-11]. VR rehabilitation motivates patients to participate in rehabilitation and improves outcomes such as postural balance, quality of life, and perceived confidence of balance [9-12].

Telerehabilitation (TR) involves different rehabilitation services via telecommunication technologies [13]. This can include interventions such as physiotherapy and allows the health professional telemonitoring and patients' teleconsultation, without their physical presence $[14,15]$. 
The usability of TR is already found in musculoskeletal and elderly patients $[16,17]$. Nevertheless, rehabilitation at home is limited by high costs and the availability of equipment [18].

Evidence is growing for of the usability of VR in neurological rehabilitation [19]. Potential benefits are found in improvement in strength, balance, gait, and level of participation. Especially for PD, MS, and stroke, there is highquality evidence that the application of VR during rehabilitation improves motor function, cognitive function, and the motivation of the patients [20-22]. For neurorehabilitation, training intensity and frequency are crucial for achieving better outcomes [8]; therefore, VR systems combined with TR provide an opportunity to increase the volume of training that healthcare providers can offer. According to our knowledge, only one review by Perrochon et al. investigated the combination of VR and TR in patients with PD, MS, or stroke [23]. However, this study does not explicitly focus on balance outcomes. It is hypothesized that continuing rehabilitation in a home-based setting can be used to improve aspects such as postural balance. Therefore, this systematic review aims to investigate what are the possible effects of using virtual reality devices in telerehabilitation conditions on the postural balance in patients with the central neurological disorders, PD, MS, or stroke. Considering the current COVID-19 situation, the need of TR usage in interventions is accelerating rapidly and the recommendations made are just as important in these days.

\section{Method}

This literature review was conducted according to the guidelines of Preferred Reporting Items for Systematic Reviews and Meta-Analysis (PRISMA) and Health Literacy [24-26].

The systematic review included articles reporting the use of VR and TR or the use of VR as a home-based rehabilitation intervention in combination with TR for telemonitoring in neurological disorders caused by PD, MS, or stroke in which primary or secondary postural outcomes were assessed. In addition, the studies must have included participants who were 18 years or older. Studies were also included if they were published in Dutch, English, or German language with no restriction on the publication date.

However, studies were excluded if they were systematic reviews, case reports, and protocols. Furthermore, studies with only gait variables and without balance outcomes were excluded.

\section{Literature search}

Studies were identified by searching electronic databases. The search was performed in PubMed, Web of Science
(WoS), ScienceDirect, the Physiotherapy Evidence Database (PEDro), and MEDLINE. The latest search was performed on February 28, 2021. The framework of Population, Intervention, Comparator, and Outcome (PICO) was used to search for eligible studies with Parkinsons Disease or Multiple Sclerosis or Stroke (P); virtual reality or telerehabilitation (I) and postural balance (O) as the search terms. The detailed search strategy can be found in the Supplementary Information. References of systematic reviews with similar research questions were also manually searched. All references were imported to EndNote online and Excel and duplicates were removed. Eligibility assessment of the first screening was performed independently by four reviewers (DB, EvZ, MC, YW), based on title and abstract. The second screening was done on full text with the inclusion and exclusion criteria by all four reviewers (DB, EvZ, MC, YW), independently. Disagreements between the reviewers were resolved by double-checking and discussion by the four reviewers to achieve consensus. During the second screening, the selection was narrowed to (pilot-) randomized controlled trials (RCTs).

Extracted data comprises of authors name, study design, study participants, intervention details, used systems, follow-up, trial setting, outcome measurements, and results for effectiveness. Two reviewers (MC, YW) extracted the data and the other reviewers (DB, EvZ) checked the extracted data. Disagreements were resolved by discussion between the four reviewers.

\section{Assessment of methodological quality}

To ascertain the validity of the eligible articles, risk of bias assessment was done independently by all four reviewers (DB, EvZ, MC, YW). The PEDro scale (PEDro, 1999), an 11-item scale, was used to briefly assess the methodological quality of the included RCTs [27]. The scores 7-8 are high-quality, 5-6 are moderate-quality, and $\leq 4$ are considered low-quality. Besides, the Cochrane collaboration risk of bias was also used to extensively assess selection, attrition, performance, detection, and reporting bias $[28,29]$. This was classified as low risk, high risk, or unclear risk of bias. Interrater reliability was measured by the weighted Fleiss Kappa in SPSS statistics V27 (IBM Corporation, New York, USA), in which higher outcomes signify a stronger agreement. Disagreements were resolved by oral discussion to achieve consensus between the four reviewers.

\section{Quantitative analysis and meta-analysis}

Review Manager (RevMan) software was used for quantitative synthesis on comparative effectiveness (RevMan V5.3, Cochrane, London, UK). Mean results and standard deviations at post-intervention were entered in RevMan by one 
author (MC) and checked by a second author (EvZ). Data of studies with scores of $\geq 5$ on the PEDro scale were used for the analysis. The outcomes concerned in this study were continuous variables. The values of outcomes post-intervention were pooled. Mean differences (MD) with $95 \%$ confidence interval (CI) were calculated with a random-effect model for all studies with the same outcome measures [30]. Subsequently, a $p$-value was checked for statistical significance. Heterogeneity was visually assessed through forest plots and $I^{2}$ statistic. Funnel plot was also used to judge publication bias.

\section{Results}

After electronic databases search and removal of duplicates, 1510 studies remained. Four hand-searched articles were added in the screening. Two screening phases were performed, and after both screening phases, seven RCTs were eligible for inclusion in the review. Figure 1 (study flowchart) shows the literature search and the study selection procedure.

\section{Study characteristics}

The demographic characteristics, intervention specifications, outcome measures, and major findings across the included studies are found in Table 1. In total, 287 participants were treated and evaluated, with a variation of 23 to 76 included participants. All three pathologies were represented in the selected studies, including PD $(n=2)$, MS $(n=2)$, and stroke $(n=3)$. The mean age varies per pathology, for PD between 67.5 and 75.4 years, for MS between 36.2 and 40.7 years, and for stroke between 55.5 and 61 years.

The interventions vary in the VR system (e.g., Nintendo Wii, Xbox 360, Microsoft Kinect, or customized designed devices) and the TR device for monitoring (e.g., Skype, Logitech webcam, or customized devices) used. Krpic et al. used two experimental groups (EGs) and all studies had a control group (CG) (conventional physiotherapy, in-clinic VR balance training, or no intervention) [31]. Prosperini et al. used two experimental groups with the same treatment, but in a different order [32]. The The main outcome, balance was measured in five studies using Berg Balance Scale (BBS), a 14-item balance scale measuring standing and transferring capabilities, rated on a 5-point scale [33].

\section{Methodological quality}

Methodological quality of the included studies is shown in Table 2. The maximum score was considered to be 8 , due to the impossibilities of blinding participants (item 5) and therapists (item 6) in intervention studies. Notable is the methodological quality of Krpic et al., which is 4 and therefore considered as a low-quality study [31]. Three studies scored 7 or 8 , and were classified as high-quality. These are Lloréns et al., Yang et al., and Hsieh [34-36]. High agreement between reviewers was found for PEDro scale (kappa: $0.860, p \leq 0.001)$. Detailed agreement between reviewers for PEDro can be found in Table 3 .

Methodological quality of each individual study and across all studies assessed using Cochrane collaboration risk of bias tool is shown in Figs. 2 and 3. Four studies used random sequence generation through computer-generated number tables [32, 34-37]; one study used wait-list randomization [38]; and one study took an algorithm using MATLAB [35]. Krpic et al. did not describe the randomization method [31]. A performance bias was shown in six studies due to the difficulty of blinding participants and personnel. Only Lloréns et al. was scored "low risk" because of the use of two therapists with one therapist blinded to allocation, gave the treatment, and assessed the participants [34]. Detection bias was unclear in two studies, and the other studies used evaluators blinded to allocation [31, 38]. Incomplete outcome data was low in four studies [32, 34, 36, 38], and the other three studies did not write about the missing data or loss-to-follow-up. The other bias was the influence of financial support, and this was high in Krpic et al. [31]. Only Gandolfi et al. showed "low risk," while the other studies were unclear about this subject [37]. There was a high agreement between the reviewers for the Cochrane risk of bias tool (kappa: $0.779, p \leq 0.001$ ). Detailed agreement between reviewers for the Cochrane risk of bias tool can be found in Tables 4 and 5.

\section{Postural balance, VR and TR}

Five studies measured postural balance using BBS, while two studies did not use BBS, but center of pressure (COP) path $[32,36]$. Prosperini et al. reported a significant difference between groups over time $(p=0.016)$ [32]. Hsieh showed significantly better performance in COP in anterior-posterior sway and the sway area between groups preintervention $(p<0.05)$ and post-intervention $(p<0.001)$ as well [36].

Table 6 shows the significance level of the BBS over time and between-group comparison. All five studies found a significant improvement overtime on the BBS in EG postintervention $(p \leq 0.05)$. There was no significant difference found between EG and CG comparison in three studies. Gandolfi et al. found a significant difference between-group comparison at post-assessment, in favor of the EG [37]. Follow-up assessment significantly improved over time on the BBS in either EG or CG, in the studies of Gandolfi et al., Novotna et al., and Yang et al. [35, 37, 38]. Between-group comparison showed no significant differences at follow-up in 


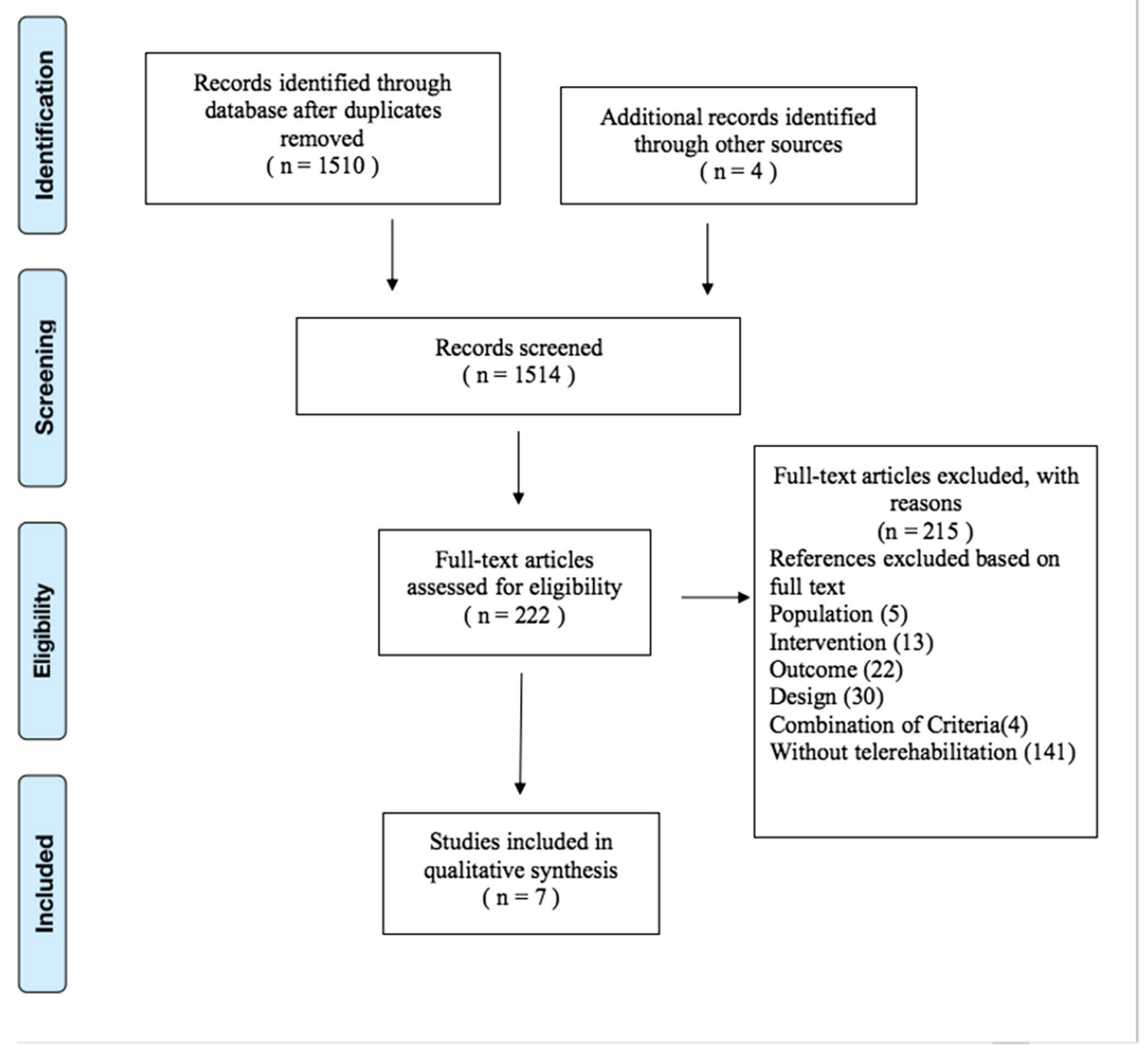

Fig. 1 Flow diagram of literature search and study selection procedure

the studies of Gandolfi et al., Llórens et al., and Yang et al. [34, 35, 37]. Krpic et al. did not find a statistical significance difference between EG1 and EG2 [31].

Result of the meta-analysis showed no statistically significant difference in BBS between EG and the CG post-intervention (MD $0.74[95 \% \mathrm{CI}-1.17,2.64] p=0.45, I^{2}=31 \%$ ) (see Fig. 4). The data of the study of Krpic et al. was not entered in RevMan because of the low-quality consideration on the PEDro scale for risk of bias [31]. The funnel plot can be found in Fig. 5.

\section{Discussion}

To our knowledge, this systematic literature review is the first to investigate the positive contribution of TR in combination with VR on postural balance in individuals with central nervous system diseases (CND), caused by PD, MS, or stroke. After comparing the assessed gait and balance parameters at baseline, there were no significant betweengroup differences. We also pooled the BBS value after intervention, and the results showed that the effectiveness of VR at home setting and TR was neither superior nor inferior to traditional therapy at improving balance. 


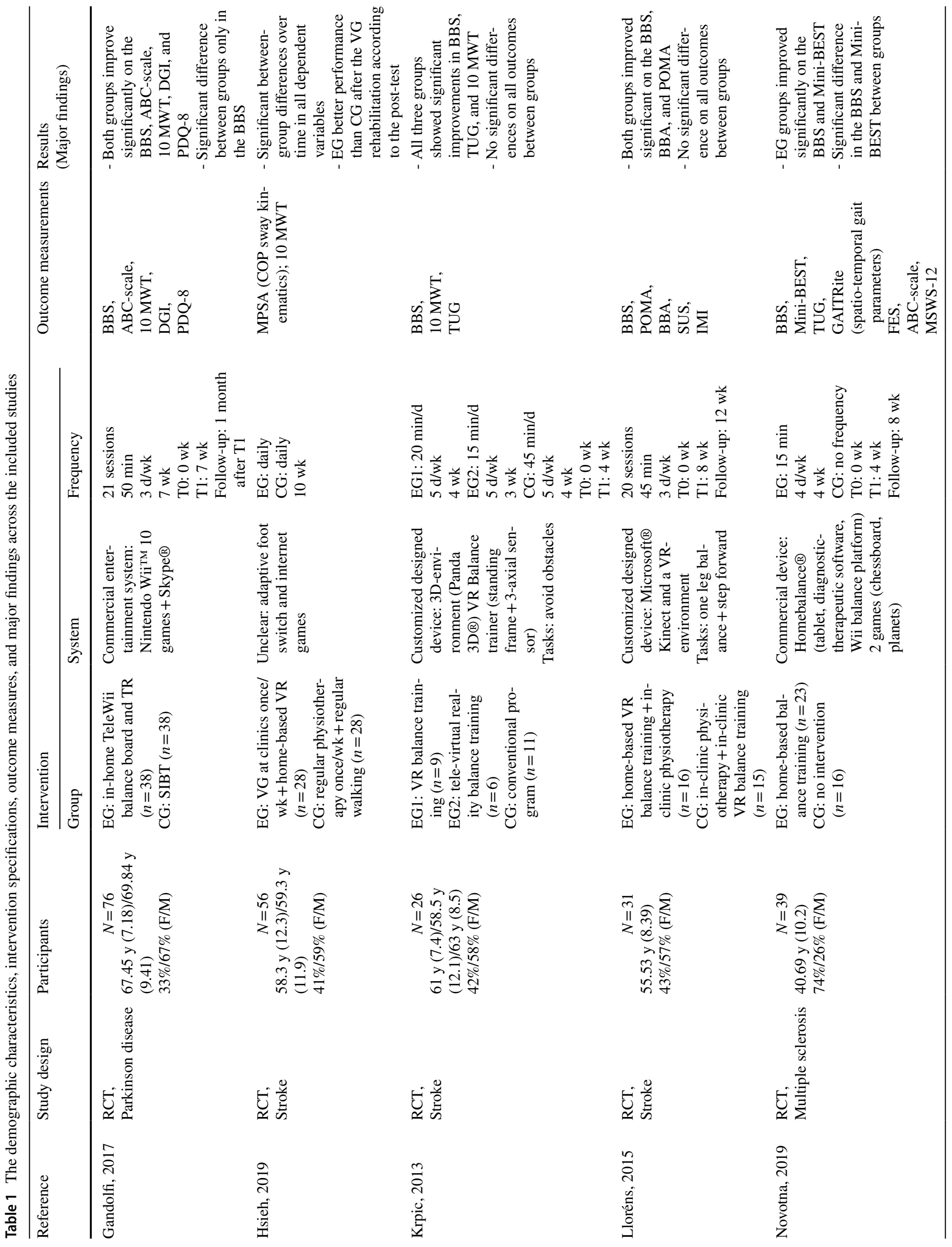




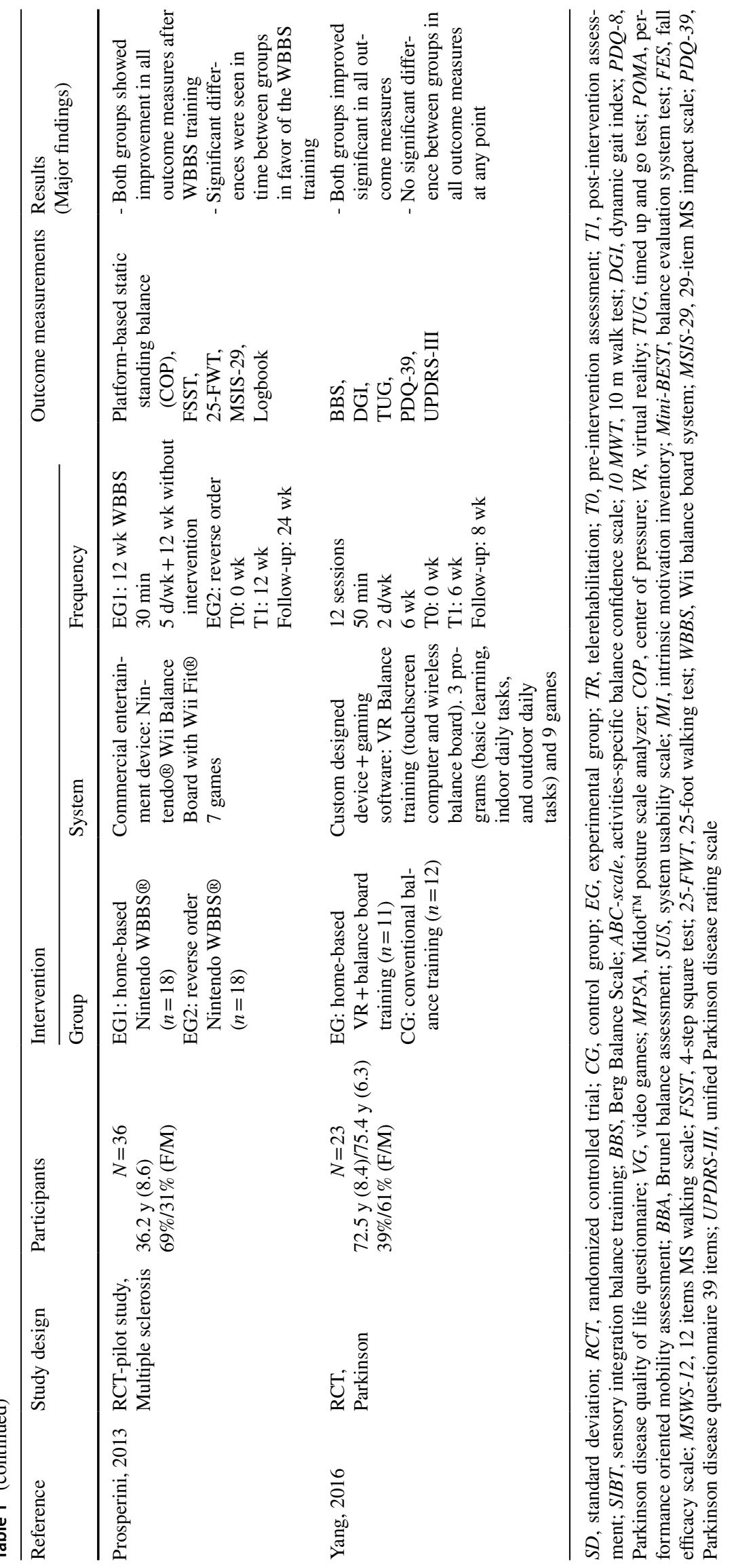


Table 2 Methodological quality of the included study

\begin{tabular}{llllll}
\hline & Rater 1 (DB) & Rater 2 (EvZ) & Rater 3 (MC) & Rater 4 (YW) & Consensus \\
\hline Gandolfi, 2017 & $6 / 10$ & $6 / 10$ & $7 / 10$ & $7 / 10$ & $8 / 10$ \\
Hsieh, 2019 & $7 / 10$ & $7 / 10$ & $7 / 10$ & $4 / 10$ & $7 / 10$ \\
Krpic, 2013 & $4 / 10$ & $4 / 10$ & $4 / 10$ & $8 / 10$ & $4 / 10$ \\
Lloréns, 2015 & $8 / 10$ & $7 / 10$ & $8 / 10$ & $4 / 10$ & $8 / 10$ \\
Novotna, 2019 & $6 / 10$ & $4 / 10$ & $5 / 10$ & $6 / 10$ & $5 / 10$ \\
Prosperini, 2013 & $6 / 10$ & $6 / 10$ & $7 / 10$ & $6 / 10$ & $7 / 10$ \\
Yang, 2014 & $7 / 10$ & $8 / 10$ & $7 / 10$ & & 70 \\
\hline
\end{tabular}

Recent published articles found similar outcomes on the effectiveness of TR interventions in individuals with neurological disorders [14, 23, 39]. Perrochon et al. reviewed the influence of exercise-based games on both upper and lower extremities and concluded that TR is a relevant alternative for rehabilitation at home [23]. Compared to Perrochon et al., this review narrowed its research down to only the postural balance [23]. Agostini et al. compared the effectiveness of TR across several diseases and found improvement following orthopedic surgery, but could not make conclusions for neurological patients [14]. Maresca et al. showed telerehabilitation can be a promising intervention for pediatric and adulthood neurological diseases, especially as regards to improving motor and cognitive outcomes [39].

\section{Effects on balance}

This review took the BBS as an outcome measure to evaluate postural balance and did a quantitative analysis on five of the seven included studies. The BBS is a worldwide known tool for measuring balance and it has been reported to be reliable and valid in PD, MS, and stroke [40, 41]. Interestingly, only Gandolfi et al. proved a significant difference between-group improvement of the EG compared to the CG on BBS scores [37]. However, we calculated the betweengroup baseline difference of his study and compared it with the between-group difference after intervention. We found a similar difference pre- and post-intervention of the between groups, which verified our results that telerehabilitation combined with VR have similar effects with usual post-clinical rehabilitation. An explanation of Gandolfi's results can be found in the sample size of the included studies [37]. Gandolfi et al. have the largest sample size $(n=75)$ [37]. Greater sample size in the other included studies would also result in stronger significance. After all, increasing the sample size gives greater power to detect differences. The second largest included study has only 39 included participants, which emphasizes this hypothesis [38].

Two of the seven included studies measured COP. Prosperini et al. mentioned COP path as a reliable ( $95 \%$ concordance correlation coefficient), more sensitive ( $88 \%$ vs $37 \%$ ), and accurate (75\% vs $63 \%$ ), but slightly less specific (67\% vs $81 \%$ ) tool [32]. Compared with a common clinical test (e.g., the Berg Balance Scale), COP path is better in predicting accidental falls over a 3-month period. This may broaden the way of analyzing balance in this specific VR treatment situation.

This review highlights the positive contribution of VR applied in home settings on balance in three different pathologies, concludes that TR interventions are as good as conventional therapy. By taking all three pathologies separately, the reviewers analyzed whether there was a difference in

Table 3 Intraclass correlation coefficient for PEDro scale

\begin{tabular}{|c|c|c|c|c|c|c|c|}
\hline & \multirow[b]{2}{*}{$\begin{array}{l}\text { Intraclass } \\
\text { correlation }^{\mathrm{b}}\end{array}$} & \multicolumn{2}{|c|}{ 95\% Confidence interval } & \multicolumn{4}{|c|}{$F$ test with true value 0} \\
\hline & & Lower bound & Upper bound & Value & df1 & df 2 & Sig \\
\hline Single measures & $.860^{\mathrm{a}}$ & .645 & .970 & 25.500 & 6 & 18 & $.000^{*}$ \\
\hline Average measures & $.961^{\mathrm{c}}$ & .879 & .992 & 25.500 & 6 & 18 & $.000^{*}$ \\
\hline
\end{tabular}

Two-way mixed effects model where people effects are random and measures effects are fixed

${ }^{a}$ The estimator is the same, whether the interaction effect is present or not

${ }^{\mathrm{b}}$ Type A intraclass correlation coefficients using an absolute agreement definition

${ }^{\mathrm{c}}$ This estimate is computed assuming the interaction effect is absent, because it is not estimable otherwise

*Statistically impossible to retrieve $p=0.000$, the significance can be interpreted $p \leq 0.001$ 


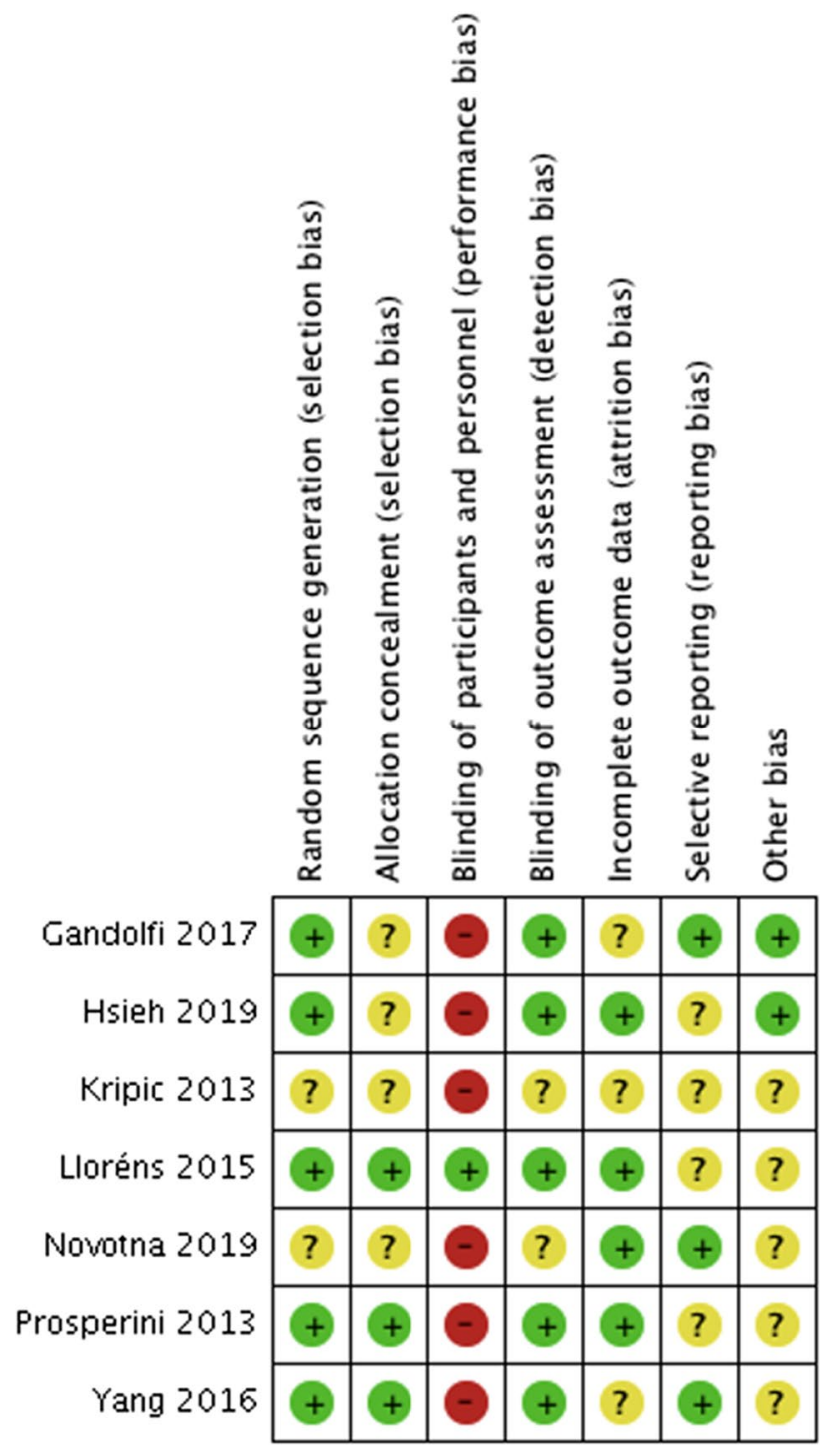

Fig. 2 Risk of bias summary of all items for each included study the application of TR between these pathologies or not. By analyzing all significance per pathology (Table 3), no different conclusions can be made; either individually taken or combined, pathologies result in the same intervention effectiveness. This shows the reviewers that TR is applicable in all included neurological disorders, which is in line with recent literature that focused on different neurological disorders as well [14, 42].

\section{Application of VR and TR}

Rehabilitation centers are increasingly using VR programs to improve motor functions and which are reported as effective in recent literature [19, 43]. However, fewer consensuses are made regarding the implementation of VR in the home setting. This first review links those two and states that TR can be used as a prolongation to the regular postclinical rehabilitation therapy to improve postural balance. The application of TR can be seen as effective, efficient, and results in more therapy compliance. Compliance can be monitored very easily, and feedback can be given regularly by videoconference. In the home-based setting environment, most investigators suggested treating plans to be monitored by at least one caregiver for safety issues when applying the telerehabilitation with VR [37, 44]. Besides, it is worth noting that during the telerehabilitation process, appropriate and accurate instructions for correcting compensations in time should be taken into consideration [45].

Variety of VR devices, such as smartphones, personal computers, commercial devices (e.g., Nintendo Wii, Xbox 360, and Homebalance), custom-designed devices, or adapted video games are a booming exercise training market. Applying VR devices in home setting will greatly motivate the patients and increase their participation, activity levels, vitality, and well-being [31, 34, 44, 46]. However, we should not ignore the need for direct communication from therapist to patients. Furthermore, therapists are able to follow more

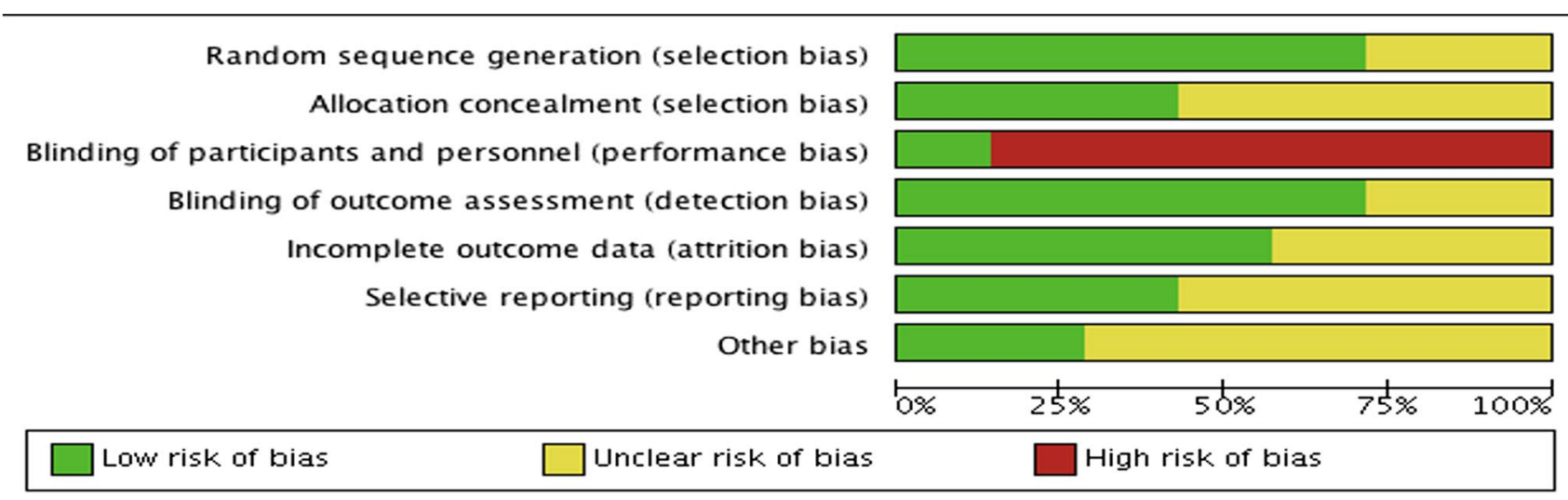

Fig. 3 Risk of bias graph of all items shown as a percentage across all included studies 
Table 4 Cochrane risk of bias outcomes of all reviewers for each included study

\begin{tabular}{|c|c|c|c|c|c|c|c|c|c|c|c|c|c|c|c|c|c|c|c|c|c|c|c|c|c|c|c|c|}
\hline & \multicolumn{4}{|c|}{$\begin{array}{c}\text { Random sequence } \\
\text { generation (Selection } \\
\text { Bias) }\end{array}$} & \multicolumn{4}{|c|}{$\begin{array}{c}\text { Allocation } \\
\text { concealment } \\
\text { (Selection bias) }\end{array}$} & \multicolumn{4}{|c|}{$\begin{array}{c}\text { Blinding of } \\
\text { participants and } \\
\text { personnel } \\
\text { (Performance bias) }\end{array}$} & \multicolumn{4}{|c|}{$\begin{array}{l}\text { Blinding of outcome } \\
\text { assessment (detection } \\
\text { bias) }\end{array}$} & \multicolumn{4}{|c|}{$\begin{array}{l}\text { Incomplete outcome } \\
\text { date (attrition bias) }\end{array}$} & \multicolumn{4}{|c|}{$\begin{array}{c}\text { Selective reporting } \\
\text { (reporting bias) }\end{array}$} & \multicolumn{4}{|c|}{ Other bias } \\
\hline & $\begin{array}{l}\text { Rater } \\
(\mathrm{OB})\end{array}$ & $\begin{array}{l}\text { Rator } \\
(\mathrm{Evz})\end{array}$ & $\begin{array}{l}\text { Rater } \\
\text { (MC) }\end{array}$ & $\begin{array}{l}\text { Rater } \\
\text { rw }\end{array}$ & $\begin{array}{l}\text { Rator } \\
\text { (DB) }\end{array}$ & $\begin{array}{l}\text { Rater } \\
(\mathrm{Evz})\end{array}$ & $\begin{array}{l}\text { Rater } \\
\text { (MC) }\end{array}$ & $\begin{array}{l}\text { Rator } \\
\text { rw }\end{array}$ & $\begin{array}{l}\text { Rator } \\
\text { (DB) }\end{array}$ & $\begin{array}{l}\text { Rater } \\
\text { (Ev2) }\end{array}$ & $\begin{array}{l}\text { Rater } \\
(M C)\end{array}$ & Rater & $\begin{array}{l}\text { Rator } \\
\text { (DB) }\end{array}$ & $\begin{array}{l}\text { Rater } \\
(\mathrm{Evz})\end{array}$ & $\begin{array}{l}\text { Rater } \\
(M C)\end{array}$ & $\begin{array}{l}\text { Rater } \\
\text { rww }\end{array}$ & $\begin{array}{l}\text { Rator } \\
(\mathrm{DB})\end{array}$ & $\begin{array}{l}\text { Ratorer } \\
\text { (Evz) }\end{array}$ & $\begin{array}{l}\text { Rater } \\
\text { (MC) }\end{array}$ & Rater & $\begin{array}{l}\text { Rater } \\
(\mathrm{DB})\end{array}$ & $\begin{array}{l}\text { Rater } \\
(\mathrm{E} \times \mathrm{z})\end{array}$ & $\begin{array}{l}\text { Rator } \\
\text { (MC) }\end{array}$ & $\begin{array}{l}\text { Rater } \\
\text { mW }\end{array}$ & $\begin{array}{l}\text { Rater } \\
(\mathrm{DB})\end{array}$ & $\begin{array}{c}\text { Rater } \\
\text { (Evz) }\end{array}$ & $\begin{array}{l}\text { Rater } \\
\text { (MC) }\end{array}$ & $\begin{array}{l}\text { Rater } \\
\mathrm{mw}\end{array}$ \\
\hline $\begin{array}{l}\text { Gandolfi, } \\
2017\end{array}$ & + & + & + & + & 1 & 1 & 1 & 1 & & & & & + & + & + & + & 1 & 1 & + & 1 & + & + & + & + & + & + & + & + \\
\hline $\begin{array}{l}\text { Hsioh, } \\
2019\end{array}$ & + & + & + & + & ! & 1 & 1 & 1 & & & & & + & + & + & 4 & + & + & + & + & 1 & 1 & 1 & $!$ & + & + & + & + \\
\hline $\begin{array}{l}\text { Kripic, } \\
2013\end{array}$ & 1 & 1 & 1 & : & $:$ & 1 & 1 & 1 & & & & & 1 & 1 & 1 & 1 & 1 & : & 1 & 1 & 1 & 1 & : & 1 & 1 & $\theta$ & 1 & $\Rightarrow$ \\
\hline $\begin{array}{l}\text { Loróns. } \\
2015\end{array}$ & + & + & + & + & + & + & + & 4 & + & + & & + & + & + & + & + & + & + & 4 & 1 & 1 & 1 & 1 & + & 1 & + & 1 & 1 \\
\hline $\begin{array}{l}\text { Novotna, } \\
2019\end{array}$ & 1 & 1 & 1 & $O$ & -1 & -1 & -1 & 1 & & & & & -1 & 1 & 1 & 1 & + & + & + & + & + & + & + & + & 1 & 1 & 1 & 1 \\
\hline $\begin{array}{l}\text { Prosoerini, } \\
2013\end{array}$ & + & + & + & + & + & + & 1 & + & & & & & + & + & + & + & + & + & + & + & 1 & 1 & $\therefore$ & -1 & 1 & 1 & + & 1 \\
\hline $\begin{array}{l}\text { Yang. } \\
2016\end{array}$ & + & 1 & + & 4 & + & 1 & 4 & 4 & & & & & 4 & + & + & + & 1 & 1 & 4 & 1 & 1 & 4 & + & + & 1 & 1 & 1 & 1 \\
\hline
\end{tabular}

Low risk of bias

Unclear risk of bias

High risk of bias

Table 5 Intraclass correlation coefficient for PEDro scale

\begin{tabular}{|c|c|c|c|c|c|c|c|}
\hline & \multirow[b]{2}{*}{$\begin{array}{l}\text { Intraclass } \\
\text { correlation }^{\text {b }}\end{array}$} & \multicolumn{2}{|c|}{ 95\% Confidence interval } & \multicolumn{4}{|c|}{$F$ test with true value 0} \\
\hline & & Lower bound & Upper bound & Value & df1 & df 2 & Sig \\
\hline Single measures & $.717^{\mathrm{a}}$ & .608 & .812 & 11.033 & 48 & 144 & .000 \\
\hline Average measures & $.910^{\mathrm{c}}$ & .861 & .945 & 11.033 & 48 & 144 & .000 \\
\hline
\end{tabular}

Two-way mixed effects model where people effects are random and measures effects are fixed

${ }^{a}$ The estimator is the same, whether the interaction effect is present or not

${ }^{\mathrm{b}}$ Type A intraclass correlation coefficients using an absolute agreement definition

${ }^{\mathrm{c}}$ This estimate is computed assuming the interaction effect is absent, because it is not estimable otherwise

* Statistically impossible to retrieve $p=0.000$, the significance can be interpreted $p \leq 0.001$

patients at the same time, which is time-efficient and costsaving [33]. Additional expected advantages are predicted on economics, automation of processes, and even on climate effect. In the acceptance of TR, social environment and usefulness play a crucial role for the patient and the therapist as well. It is recommended that the application of VR in the home setting is easy to use, and the perceived usefulness is seen as an important predictor for compliance [46].

\section{Limitations}

Several limitations of this literature review should be acknowledged. First, the relatively small sample sizes of the included studies can be seen as a limitation. The restriction of small sample sizes is common in the literature of neurorehabilitation because of difficult patient recruitment, the broad range of disability experienced by patients, and

Table 6 Significance level of the BBS over time and between-group comparison

\begin{tabular}{|c|c|c|c|c|c|c|c|c|c|}
\hline Study name & Disease & $\begin{array}{l}\text { MD CG } \\
\text { (post) }\end{array}$ & $\begin{array}{l}\text { MD CG } \\
\text { (follow-up) }\end{array}$ & $\begin{array}{l}\text { MD EG } \\
\text { (post) }\end{array}$ & $\begin{array}{l}\text { MD EG } \\
\text { (follow-up) }\end{array}$ & $\begin{array}{l}\text { MD EG2 } \\
\text { (post) }\end{array}$ & $\begin{array}{l}\text { Between- } \\
\text { group differ- } \\
\text { ence CG-EG } \\
\text { (post) }\end{array}$ & $\begin{array}{l}\text { Between- } \\
\text { group differ- } \\
\text { ence CG-EG } \\
\text { (follow-up) }\end{array}$ & $\begin{array}{l}\text { Between- } \\
\text { group } \\
\text { difference } \\
\text { EG1-EG2 } \\
\text { (post) }\end{array}$ \\
\hline $\begin{array}{c}\text { Gandolfi, } \\
2017\end{array}$ & PD & $<0.001$ & 0.002 & $<0.001$ & $<0.001$ & & 0.02 & $>0.05^{*}$ & \\
\hline Krpic, 2013 & Stroke & 0.007 & & 0.006 & & 0.018 & 0.697 & & 0.988 \\
\hline $\begin{array}{l}\text { Lloréns, } \\
2015\end{array}$ & Stroke & 0.001 & $>0.005^{*}$ & 0.001 & $0.05 *$ & & $0.05 *$ & $>0.05^{*}$ & \\
\hline $\begin{array}{c}\text { Novotna, } \\
2019\end{array}$ & MS & 0.189 & & 0.001 & $0.05 *$ & & & & \\
\hline Yang, 2016 & PD & 0.001 & 0.003 & 0.001 & 0.003 & & $0.05^{*}$ & $>0.05^{*}$ & \\
\hline
\end{tabular}

*No exact data known, only described as (not) statistically significant. A significant level is reached at $p \leq 0.05$ 


\begin{tabular}{|c|c|c|c|c|c|c|c|}
\hline \multirow[b]{2}{*}{ Study or Subgroup } & \multicolumn{3}{|c|}{ Experimental } & \multicolumn{3}{|c|}{ Control } & \multirow[b]{2}{*}{ Weight } \\
\hline & Mean & SD & Total & Mean & SD & Total & \\
\hline Gandolfi 2017 & 52.37 & 3.29 & 38 & 49.82 & 5.7 & 38 & $40.8 \%$ \\
\hline Lloréns 2015 & 51.2 & 2.11 & 16 & 51.07 & 5.09 & 15 & $29.7 \%$ \\
\hline Novotna 2019 & 50.7 & 8.69 & 23 & 52.19 & 5.07 & 16 & $15.5 \%$ \\
\hline Yang 2016 & 50.3 & 5.4 & 11 & 51.1 & 5.9 & 12 & $14.0 \%$ \\
\hline Total $(95 \% \mathrm{Cl})$ & & & 88 & & & 81 & $100.0 \%$ \\
\hline
\end{tabular}

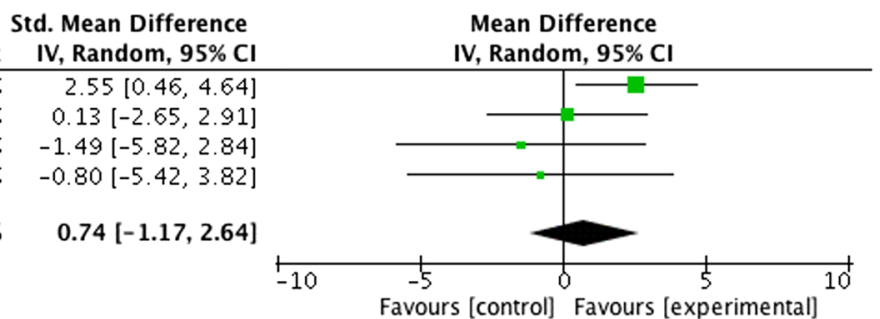

Fig. 4 Comparison between EG and CG in BBS post-intervention

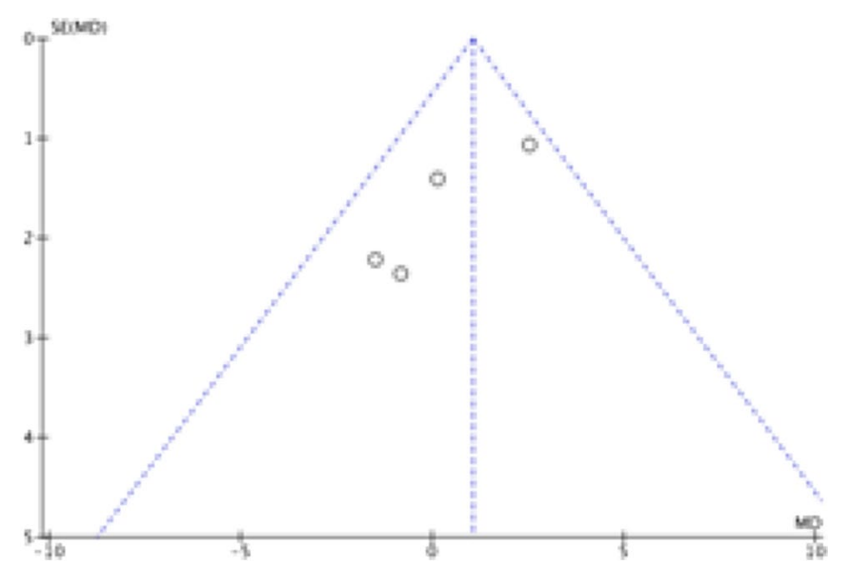

Fig. 5 Funnel plot

difficulties in predicting prognosis $[47,48]$. Secondly, the heterogeneity of the included studies is difficult to identify due to different conditions and interventions used. It is known that PD and MS do have a progressive course of pathology, while the recovery of stroke can be seen as regressive. This natural course of recovery in stroke could influence the outcome. Future trials should include larger sample size and standard protocols to better assess the validity of this promising tool.

\section{Clinical practice and future research}

Despite the lack of significant difference in the use of TR compared to conventional therapy, all included studies show a significant improvement in balance measured with BBS. Thus, the results from this review provides evidence that TR opens new opportunities for treating postural instability, giving individuals the opportunity to train from the familiar environment of their home. Home-based rehabilitation can be time- and cost-effective for the patient and the rehabilitation center. In addition, commercial entertainment devices such as the Wii Fit and Microsoft Kinect are easily accessible for private use. This allows the patient to create a homebased rehabilitation setting in an accessible way.
It is widely known that there is a growing interest in the modern world regarding the implementation of VR programs in neurorehabilitation [8, 43]. Many studies aimed to investigate the VR setting and its implementation in neurorehabilitation setting. According to the authors, it is suggested that further research should be more focused on the implementation of VR in TR. Moreover, the authors suggest to investigate the usefulness of VR in TR at a financial level since this proposal appears to be time- and cost-effective. However, only a few of the included studies described the cost-effectiveness of TR in the neurorehabilitation and most did not provide details on that. Since the results of this study suggest TR is applicable in the neurorehabilitation, a more detailed financial insight is recommended.

\section{Conclusion}

Although the effectiveness of home-based VR and TR was neither superior nor inferior to conventional therapy, they can be used as an augmentation to conventional post-clinical rehabilitation programs. In addition, they can also be used to help prolong rehabilitation time in order to maximize clinical benefits for patients. This is especially important considering the current COVID-19 situation, when the need of TR usage in interventions is accelerating rapidly because of measures and regulations to prevent or reduce the spread of the infection.

Supplementary Information The online version contains supplementary material available at https://doi.org/10.1007/s10072-021-05855-2.

Author contribution Design: all authors; execution: DB, EVZ, MC, YW, and NS; analysis: DB, EVZ, MC, YW, NS, ST, and WS; and writing and editing of final version of the manuscript: all authors.

\section{Declarations}

Conflict of interest The authors declare no competing interests.

Ethical approval Not Applicable.

Consent Statement Not Applicable. 


\section{References}

1. Feigin VL, Nichols E, Alam T, Bannick MS, Beghi E, Blake N et al (2019 May 1) Global, regional, and national burden of neurological disorders, 1990-2016: a systematic analysis for the Global Burden of Disease Study 2016. Lancet Neurol 18(5):459-480. https://doi.org/10.1016/S1474-4422(18)30499-X

2. Feigin VL, Abajobir AA, Abate KH, Abd-Allah F, Abdulle AM, Abera SF, Aichour MTE (2017 Nov) Global, regional, and national burden of neurological disorders during 1990-2015: a systematic analysis for the Global Burden of Disease Study 2015. Lancet Neurol 16(11):877-897. https://doi.org/10.1016/S14744422(17)30299-5

3. World Health Organization, editor. Neurological disorders: public health challenges. Geneva: World Health Organization; 2006. 218 p. Available from: https://www.who.int/mental_health/neurology/ neurological_disorders_report_web.pdf. Accessed Sep 2021

4. Nederlandse Vereniging voor Neurologie. Multiple sclerose. Federatie Medisch Specialisten. Published 2012. https://richt lijnendatabase.nl/richtlijn/multipele_sclerose/multipele_scler ose_-startpagina.html\#tab-content-accountability

5. Van Nimwegen M, Nijkrake M, Munneke M, de Groot D, Heijblom KG, Meerhoff GA. KNGF-richtlijn ziekte van Parkinson. 19:26. Available from: https://www.parkinsonnet.nl/app/uploads/ 2019/11/KNGF-richtlijn-Ziekte-van-Parkinson-Praktijkrichtlijn. pdf

6. Veerbeek, J.M., Van Wegen, E.E.H., Van Peppen, R.P.S., Hendriks, H.J.M., Rietberg, M.B., Van der Wees, J., ... \& Kwakkel, G. (2014). KNGF-richtlijn Beroerte. Koninklijk Nederlands Genootschap voor Fysiotherapie. Avaliable from https://www. kennisnetwerkcva.nl/wp-content/uploads/2018/08/KNGF-Richt lijn-Beroerte-2014-inclusief-update-klinimetrie-2017.pdf

7. Nielsen JB, Willerslev-Olsen M, Christiansen L, LundbyeJensen J, Lorentzen J (2015) Science-based neurorehabilitation: recommendations for neurorehabilitation from basic science. $\mathrm{J}$ Mot Behav 47(1):7-17. https://doi.org/10.1080/00222895.2014. 931273

8. O'Neil O, Fernandez MM, Herzog J et al (2018) Virtual reality for neurorehabilitation: insights from 3 European clinics. PM R 10(9 Suppl 2):S198-S206. https://doi.org/10.1016/j.pmrj.2018.08.375

9. Lee H, Park Y, Park S (2019) The effects of virtual reality training on function in chronic stroke patients: a systematic review and meta-analysis. BioMed Res Int 2019:1-12. https://doi.org/ 10.1155/2019/7595639

10. Weiss PL, Kizony R, Feintuch U, Katz N. Virtual reality in neurorehabilitation. In: Gage F, Cohen L, Selzer M, Duncan P, Clarke S, eds. Textbook of neural repair and rehabilitation: volume 2: medical neurorehabilitation. Vol 2. Cambridge University Press; 2006:182-197. https://doi.org/10.1017/CBO9780511545078.015

11. Abbadessa G, Brigo F, Clerico M, De Mercanti S, Trojsi F, Tedeschi G, Bonavita S, Lavorgna L. Digital therapeutics in neurology. J Neurol. https://doi.org/10.1007/s00415-021-10608-4

12. Lei C, Sunzi K, Dai F et al (2019) Effects of virtual reality rehabilitation training on gait and balance in patients with Parkinson's disease: a systematic review. PLoS ONE 14(11):e0224819. https:// doi.org/10.1371/journal.pone.0224819

13. Piron L, Turolla A, Agostini M et al (2009) Exercises for paretic upper limb after stroke: a combined virtual-reality and telemedicine approach. J Rehabil Med 41(12):1016-1102. https://doi.org/ 10.2340/16501977-0459

14. Agostini M, Moja L, Banzi R et al (2015) Telerehabilitation and recovery of motor function: a systematic review and meta-analysis. J Telemed Telecare 21(4):202-213. https://doi.org/10.1177/ $1357633 \mathrm{X} 15572201$
15. Piron L, Tonin P, Trivello E, Battistin L, Dam M (2004) Motor tele-rehabilitation in post-stroke patients. Med Inform Internet Med 29(2):119-125. https://doi.org/10.1080/146392304100017 23428

16. De Luca R, Bramanti A, De Cola MC et al (2016) Tele-health-care in the elderly living in nursing home: the first Sicilian multimodal approach. Aging Clin Exp Res 28(4):753-759. https://doi.org/10. 1007/s40520-015-0463-8

17. Grona SL, Bath B, Busch A, Rotter T, Trask C, Harrison E (2018) Use of videoconferencing for physical therapy in people with musculoskeletal conditions: a systematic review. J Telemed Telecare 24(5):341-355. https://doi.org/10.1177/1357633X17700781

18. Calabrò RS, Bramanti A, Garzon M et al (2018) Telerehabilitation in individuals with severe acquired brain injury: rationale, study design, and methodology. Medicine (Baltimore) 97(50):e13292. https://doi.org/10.1097/MD.0000000000013292

19. Massetti T, da Silva TD, Crocetta TB et al (2018) The clinical utility of virtual reality in neurorehabilitation: a systematic review. J Cent Nerv Syst Dis 10:1179573518813541. https://doi.org/10. $1177 / 1179573518813541$

20. Dockx K, Bekkers EM, Van den Bergh V et al (2016) Virtual reality for rehabilitation in Parkinson's disease. Cochrane Database Syst Rev. 12(12):CD010760. https://doi.org/10.1002/14651858. CD010760.pub2

21. Karamians R, Proffitt R, Kline D, Gauthier LV (2020) Effectiveness of virtual reality- and gaming-based interventions for upper extremity rehabilitation poststroke: a meta-analysis. Arch Phys Med Rehabil 101(5):885-896. https://doi.org/10.1016/j.apmr. 2019.10.195

22. Maggio MG, Russo M, Cuzzola MF et al (2019) Virtual reality in multiple sclerosis rehabilitation: a review on cognitive and motor outcomes. J Clin Neurosci Off J Neurosurg Soc Australas 65:106-111. https://doi.org/10.1016/j.jocn.2019.03.017

23. Perrochon A, Borel B, Istrate D, Compagnat M, Daviet J-C (2019) Exercise-based games interventions at home in individuals with a neurological disease: a systematic review and meta-analysis. Ann Phys Rehabil Med 62(5):366-378. https://doi.org/10.1016/j.rehab. 2019.04.004

24. Liberati A, Altman DG, Tetzlaff J et al (2009) The PRISMA statement for reporting systematic reviews and meta-analyses of studies that evaluate health care interventions: explanation and elaboration. PLoS Med 6(7):e1000100. https://doi.org/10.1371/ journal.pmed. 1000100

25. Meeus M, Gebruers N (2016) Health literacy, from reference to review, 1st edn. Acco, Leuven

26. Moher D, Liberati A, Tetzlaff J, Altman DG (2009) Preferred reporting items for systematic reviews and meta-analyses: the PRISMA statement. PLoS Med 6(7):e1000097. https://doi.org/ 10.1371/journal.pmed.1000097

27. PEDro. PEDro scale. [Measurement instrument]. Published online June 21, 1999. https://www.pedro.org.au/english/downloads/ pedro-scale/

28. Higgins, J. P. \& Green, S. Cochrane handbook for systematic reviews of interventions (version 5.1). [Epub]. John Wiley \& Sons. www.handbook.cochrane.org

29. Sterne, J.A.C, Savović, J., Page, M.J., Elbers, R.G., Blencowe, N.S., Boutron, I., ... \& Higgins, J.P. RoB 2: a revised tool for assessing risk of bias in randomised trials. $B M J$. Published online 2019:366. https://doi.org/10.1136/bmj.14898

30. Borenstein, M., Hedges, L.V., Higgins, J.P.T. \& Rothstein, H.R. Introduction to meta-analysis. John Wiley \& Sons, Ltd.; 2009. https://doi.org/10.1002/9780470743386

31. Krpič A, Savanović A, Cikajlo I (2013) Telerehabilitation: remote multimedia-supported assistance and mobile monitoring of balance training outcomes can facilitate the clinical staff's effort. Int 
J Rehabil Res Int Z Rehabil Rev Int Rech Readaptation 36(2):162171. https://doi.org/10.1097/MRR.0b013e32835dd63b

32. Prosperini L, Fortuna D, Giannì C, Leonardi L, Marchetti MR, Pozzilli C (2013) Home-based balance training using the Wii balance board: a randomized, crossover pilot study in multiple sclerosis. Neurorehabil Neural Repair 27(6):516-525. https://doi. org/10.1177/1545968313478484

33. Berg K, Wood-Dauphine S, Williams JI, Gayton D (1989) Measuring balance in the elderly: preliminary development of an instrument. Physiother Can 41(6):304-311. https://doi.org/10.3138/ptc. 41.6.304

34. Lloréns R, Noé E, Colomer C, Alcañiz M (2015) Effectiveness, usability, and cost-benefit of a virtual reality-based telerehabilitation program for balance recovery after stroke: a randomized controlled trial. Arch Phys Med Rehabil 96(3):418-425.e2. https:// doi.org/10.1016/j.apmr.2014.10.019

35. Yang W-C, Wang H-K, Wu R-M, Lo C-S, Lin K-H (2016) Homebased virtual reality balance training and conventional balance training in Parkinson's disease: a randomized controlled trial. J Formos Med Assoc Taiwan Yi Zhi 115(9):734-743. https://doi. org/10.1016/j.jfma.2015.07.012

36. Hsieh H-C (2019) Training by using an adaptive foot switch and video games to improve balance and mobility following stroke: a randomised controlled trial. Brain Impair 20(1):16-23. https:// doi.org/10.1017/BrImp.2018.15

37. Gandolfi M, Geroin C, Dimitrova E et al (2017) Virtual reality telerehabilitation for postural instability in Parkinson's disease: a multicenter, single-blind, randomized, controlled trial. BioMed Res Int 2017:7962826. https://doi.org/10.1155/2017/7962826

38. Novotna K, Janatova M, Hana K, Svestkova O, Preiningerova Lizrova J, Kubala HE (2019) Biofeedback based home balance training can improve balance but not gait in people with multiple sclerosis. Mult Scler Int 2019:e2854130. https://doi.org/10.1155/ 2019/2854130

39. Maresca G, Maggio MG, De Luca R, et al. Tele-neuro-rehabilitation in Italy: state of the art and future perspectives. Front Neurol. 2020;11. https://doi.org/10.3389/fneur.2020.563375

40. Tyson SF, Connell LA (2009) How to measure balance in clinical practice A systematic review of the psychometrics and clinical utility of measures of balance activity for neurological conditions.
Clin Rehabil. 23(9):824-840. https://doi.org/10.1177/0269215509 335018

41. Qutubuddin AA, Pegg PO, Cifu DX, Brown R, McNamee S, Carne W (2005) Validating the Berg Balance Scale for patients with Parkinson's disease: a key to rehabilitation evaluation. Arch Phys Med Rehabil 86(4):789-792. https://doi.org/10.1016/j.apmr. 2004.11.005

42. Juras G, Brachman A, Michalska J et al (2019) Standards of virtual reality application in balance training programs in clinical practice: a systematic review. Games Health J 8(2):101-111. https://doi.org/10.1089/g4h.2018.0034

43. Howard MC (2017) A meta-analysis and systematic literature review of virtual reality rehabilitation programs. Comput Hum Behav 70:317-327. https://doi.org/10.1016/j.chb.2017.01.013

44. Lin K-H, Chen C-H, Chen Y-Y et al (2014) Bidirectional and multi-user telerehabilitation system: clinical effect on balance, functional activity, and satisfaction in patients with chronic stroke living in long-term care facilities. Sensors 14(7):12451-12466. https://doi.org/10.3390/s140712451

45. Kato N, Tanaka T, Sugihara S, Shimizu K (2015) Development and evaluation of a new telerehabilitation system based on VR technology using multisensory feedback for patients with stroke. J Phys Ther Sci 27(10):3185-3190. https://doi.org/10.1589/jpts. 27.3185

46. Thomas S, Fazakarley L, Thomas PW et al (2017) Mii-vitaliSe: a pilot randomised controlled trial of a home gaming system (Nintendo Wii) to increase activity levels, vitality and well-being in people with multiple sclerosis. BMJ Open 7(9):e016966. https:// doi.org/10.1136/bmjopen-2017-016966

47. Cheeran B, Cohen L, Dobkin B et al (2009) The future of restorative neurosciences in stroke: driving the translational research pipeline from basic science to rehabilitation of people after stroke. Neurorehabil Neural Repair 23(2):97-107. https://doi.org/10. 1177/1545968308326636

48. Page SJ, Gater DR, Bach-Y-Rita P (2004) Reconsidering the motor recovery plateau in stroke rehabilitation. Arch Phys Med Rehabil 85(8):1377-1381. https://doi.org/10.1016/j.apmr.2003.12.031

Publisher's note Springer Nature remains neutral with regard to jurisdictional claims in published maps and institutional affiliations. 